\title{
Research and Analysis on the Principle in Plant Cold Recycling for Foamed Bitumen and Mixture Performance
}

\author{
Zecheng Ni, Shijing Chen, Yihuan Li, Hongxi Peng, Jiawen Liang, Congrong Tang* \\ TSchool of Civil and Construction Engineering, Nanjing TECH University Pujiang Instttute, Nanjing 211134, China
}

Funding: This article is the research result of the project "Research and Analysis of the Recycling and Utilization of Waste Concrete Based on Energy-saving and Environmental Protection" PJ20201390519 of the project of "Innovation and Entrepreneurship Training Program for College Students in 2020". Instructor: Congrong Tang

\begin{abstract}
The early asphalt pavement in our country severely reduced the road performance due to various external factors during the use process. According to incomplete statistics, there are more asphalt pavements that need to be renovated and repaired every year in China, and the amount of construction waste such as asphalt concrete and other construction waste reaches 1,000 . About ten thousand tons. If such a huge amount of construction waste is not used, it will inevitably cause great pollution to the environment. If it can be reused, not only will it be environmentally friendly and energy-saving, it will also save more than one billion yuan in costs. In view of the above problems, this article conducts related Research and Analysis on the Principle in Plant Cold Recycling for Foamed Bitumen and Mixture Performance to provide reference for future projects.
\end{abstract}

Keywords: Foamed Bitumen; In Plant Cold Recycling; Mix design; Mixture performance

Publication date: November, 2020

Publication online: 30 November, 2020

"Corresponding author: Congrong Tang, ter751101 @163.com

\section{Introduction}

With the increase in traffic volume, the increase in heavy vehicles and the increase in road service time, road damage is becoming more and more serious. A large number of roads enter the stage of maintenance, repair and renovation. The construction waste generated by renovation and repair is reasonable and effective because there is no relevant technology. It is discarded due to the use of it, resulting in waste of resources and environmental pollution. Recycling and recycling the construction waste generated during construction not only saves resources but also reduces environmental pollution, and has great economic and social benefits. Carrying out the research and analysis of the cold recycling principle of foamed asphalt plant mix and the performance of the mixture can solve some of the above-mentioned problems and have certain research value.

\section{The principle of cold recycling of foamed asphalt plant mix}

Cold recycling of asphalt pavement refers to the technology and method that can be reused after processing the asphalt pavement milling mixture damaged by overload, fatigue, aging, etc. under normal temperature conditions ${ }^{[1]}$. Foamed bitumen refers to the bitumen in which a small amount of water and air are added to the hot bitumen, and the bitumen is formed into a fine foam in an expanded state through professional foaming equipment ${ }^{[1]}$. The foaming principle is mainly that the hightemperature asphalt, water, and air are mixed and the high-temperature asphalt heats the water to generate a steam bubble with a certain tension to expand the asphalt to form an asphalt film. After a few seconds, the expansion disappears, the asphalt viscosity decreases, and the gap between the wet aggregates It 
is easily penetrated by asphalt. The foaming principle is shown in Figure 1. The foaming equipment is equipped with a regular cleaning and opening device for nozzles, which can ensure that water, air and foamed asphalt are sprayed at the same time, and the spray amount can also be effectively controlled.

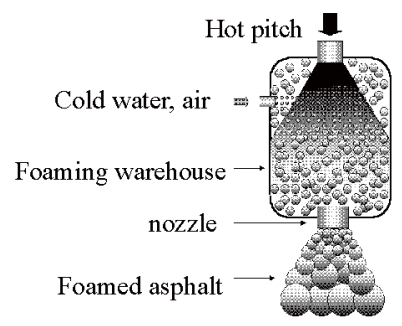

Figure 1. Asphalt foaming principle

According to the principle of asphalt foaming, two important parameters of foamed asphalt are expansion rate and half-life. Expansion rate refers to the ratio of the maximum expansion volume of asphalt in the foamed state to the original volume of asphalt. Asphalt mixture requires a good package between asphalt and aggregate. The expansion rate of asphalt should be higher. The higher the expansion rate of asphalt, the higher the expansion rate of asphalt, the foamed asphalt mixture The better the material carrying capacity. The half-life refers to the time it takes for the foamed asphalt to decay from the maximum expansion volume to $1 / 2$. The longer the half-life, the more opportunities for the asphalt to contact the aggregate, the more fully the aggregate gap is filled with asphalt, and the foamed asphalt mixture bears The better the capacity, the length of the half-life reflects the stability of the foamed asphalt. The longer the half-life, the better the stability of the foamed asphalt, and vice versa.

Foamed asphalt plant mixing cold recycling is to transport the asphalt mixture milled out of the damaged asphalt pavement to a designated mixing site according to requirements. After adding new materials, add foamed asphalt and use recycling equipment to stir at room temperature to generate new mixed materials. The construction technology of paving and compaction by transporting equipment to the construction site to form a structural layer ${ }^{[1]}$, the production process of foamed asphalt recycled mixture is shown in Figure 2. As the foam will decay over time, it is required that the foaming of the foamed asphalt recycled mixture during the mixing process and the transportation of the recycled asphalt surface material and the new aggregate must be consistent to ensure that the foamed asphalt decays within the effective period Complete the mixing of the recycled mixture.

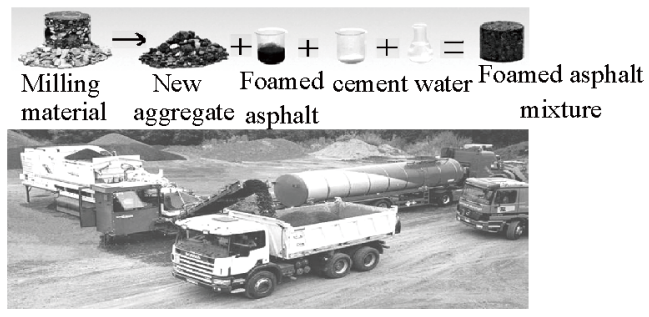

Figure 2. The production process of foamed asphalt recycled mixture

\section{Testing of raw materials for cold recycled mixture test in foamed asphalt plant}

\subsection{Test of recycled asphalt pavement materials}

The recycled bitumen surface material should be classified and screened, and the silo recycled materials should be used up within the specified time, and waterproof measures should be taken. The test recycled asphalt pavement materials should be representative, and the test results can show the true condition of the original asphalt pavement. The recycled asphalt surface material should be free from soil agglomeration and other pavement materials. The test of recycled asphalt pavement materials is mainly to dry the milled asphalt mixture for screening and extraction tests. The test of recycling asphalt pavement materials requires the oven to be maintained at about $60^{\circ} \mathrm{C}$ and the drying time to be maintained for 24 hours $^{[1]}$. See Table 1 for the screening and extraction test results of recycled asphalt pavement materials.

Table 1. Screening and extraction test results of recycled asphalt pavement materials

\begin{tabular}{|c|c|c|c|c|c|c|c|c|c|c|c|c|c|}
\hline Mesh size $(\mathrm{mm})$ & 31.5 & 26.5 & 19 & 16 & 13.2 & 9.5 & 4.75 & 2.36 & 1.18 & 0.6 & 0.3 & 0.15 & 0.075 \\
\hline Screening pass rate & 100 & 96.2 & 88.6 & 71.4 & 60.1 & 48.9 & 36.7 & 30.6 & 23.4 & 16.9 & 12.8 & 8.1 & 3.9 \\
\hline Extraction pass rate & 100 & 97.6 & 91.8 & 77.8 & 66.9 & 49.1 & 39.8 & 28.1 & 21.9 & 14.1 & 12.1 & 9.2 & 5.9 \\
\hline Asphalt content $(\%)$ & & & & & & & 3.79 & & & & & & \\
\hline
\end{tabular}




\subsection{Asphalt}

The asphalt used for foaming must meet the requirements of the specification, the wrapping capacity must be strong, and the adaptability must be good. The mixed foamed asphalt concrete has good water resistance and high early strength. Modified asphalt cannot be used as the foamed asphalt. The test uses $70^{\#}$ road petroleum asphalt as the test asphalt. The test results are shown in Table 2. The test results show that the asphalt meets the requirements ${ }^{[1-2]}$.

Table 2. Test results of asphalt test

\begin{tabular}{|c|c|c|c|}
\hline Technical index & Penetration $\left(25^{\circ} \mathrm{C}, 5 \mathrm{~s}, 100 \mathrm{~g}\right)$ & Softening Point, ${ }^{\circ} \mathrm{C}$ & Ductility $\left(15^{\circ} \mathrm{C}\right), \mathrm{cm}$ \\
\hline Test results & 71.2 & 47.8 & $>100$ \\
\hline skills requirement & $60-80$ & $\geq 46$ & $\geq 100$ \\
\hline
\end{tabular}

\subsection{Aggregate}

The quality and gradation of the aggregate should meet the specification requirements, and the aggregate should be dry and free of impurities. Limestone was selected as the coarse aggregate for the test. The test results of the coarse and fine aggregates are shown in Table 3 to Table5. It can be seen from the test results that the aggregate meets the requirements ${ }^{[1,3]}$.

Table 3. Coarse aggregate quality test results

\begin{tabular}{cccc}
\hline Technical index & Stone crushing value (\%) & Apparent relative density & Needle flake particle content (\%) \\
\hline Test results & 15 & 2.637 & 9.8 \\
Design requirements & $\leq 24$ & $\geq 2.45$ & $\leq 15$ \\
\hline
\end{tabular}

Table 4. Fine aggregate quality inspection results

\begin{tabular}{cccc}
\hline Technical index & Apparent relative density & Sand equivalent (\%) & Moisture content (\%) \\
\hline Test results & 2.632 & 62.8 & 2.986 \\
Design requirements & $\geq 2.45$ & $\geq 60$ & $\leq 4$ \\
\hline
\end{tabular}

Table 5. Screening test results of coarse and fine aggregates

\begin{tabular}{ccccccccccccc}
\hline Mesh size $(\mathrm{mm})$ & 31.5 & 26.5 & 19 & 13.2 & 9.5 & 4.75 & 2.36 & 1.18 & 0.6 & 0.3 & 0.15 & 0.075 \\
\hline Coarse aggregate pass rate & 100 & 84.1 & 11.4 & 0.6 & 0.4 & 0.4 & 0.3 & 0.3 & 0.3 & 0.3 & 0.3 & 0.3 \\
Fine aggregate passing rate & 100 & 100 & 100 & 100 & 100 & 100 & 80.8 & 51.9 & 35.1 & 22.2 & 13.5 & 12.1 \\
\hline
\end{tabular}

\subsection{Cement}

The cement used for the foamed asphalt mixture should be low-strength cement, which should meet the requirements of the specification. The test uses P.C32.5 composite Portland cement, and the cement addition ratio is $1.5 \%$ to improve the foamed asphalt recycled mixture. Early strength and water stability.
At the same time, part of the cement is used as the filler of the foamed asphalt recycled mixture to enhance the performance of the foamed asphalt recycled mixture. The cement test results are shown in Table6. The test results show that the cement meets the requirements ${ }^{[1,3]}$.

Table 6. Cement test results

\begin{tabular}{|c|c|c|c|c|c|c|c|c|}
\hline \multirow{2}{*}{$\begin{array}{l}\text { Technical } \\
\text { index }\end{array}$} & \multirow{2}{*}{ Stability } & \multirow{2}{*}{$\begin{array}{c}\text { Fineness } \\
(80 \mu \mathrm{m}) \\
(\%)\end{array}$} & \multirow{2}{*}{$\begin{array}{l}\text { Initial } \\
\text { setting } \\
\text { time(h) } \\
\end{array}$} & \multirow{2}{*}{$\begin{array}{l}\text { Final setting } \\
\text { time(h) }\end{array}$} & \multicolumn{2}{|c|}{ Flexural strength (MPa) } & \multicolumn{2}{|c|}{ Compressive strength (MPa) } \\
\hline & & & & & 3d & 28d & 3d & 28d \\
\hline Test results & 1.4 & 3.4 & 4.3 & 4.5 & 4.3 & 7.9 & 20.2 & 36.7 \\
\hline Design requirements & $\leq 5.0$ & $\leq 10$ & $\geq 3$ & $\leq 10$ & $\geq 3.5$ & $\geq 5.5$ & $\geq 15.0$ & $\geq 32.0$ \\
\hline
\end{tabular}

4 Mix ratio design of cold recycled mixture in foamed asphalt plant

\subsection{Gradation design of foamed asphalt plant mixed cold recycled mixture engineering}

The design of the synthetic gradation of the cold foamed asphalt plant mixed recycled mixture should meet the requirements of the specification ${ }^{[4]}$. According to the traffic conditions and the actual road conditions, the preliminary design of the gradation design test of the cold foamed asphalt plant mixed recycled mixture For: Gradation A: cement (1.5\%), stone chips (10\%), milling material (90\%); Gradation B: cement (1.5\%), gravel (5\%), stone chips $(10 \%)$, 
Milling material (85\%); Gradation C: cement (1.5\%), crushed stone $(5 \%)$, stone chips $(8 \%)$, milling material (87\%), sieved by three schemes of screening test The curve is shown in Figure 3, and it can be seen from the curve in the Figure 3 that all three solutions meet the requirements.

\subsection{The amount of foamed asphalt}

According to the grading range of the synthetic mixture and the original asphalt content, the estimated foamed asphalt consumption of the above three grading schemes is shown in Table 7 below.

Table 7. Estimated amount of foamed asphalt

\begin{tabular}{cccc}
\hline ndex & Gradation A & Gradation B & Gradation C \\
\hline Original asphalt content (\%) & 3.4 & 3.2 & 3.3 \\
Estimated amount of foamed asphalt BC (\%) & 2.0 & 2.2 & 2.1 \\
\hline
\end{tabular}

\subsection{Determine the optimal moisture content}

For foamed asphalt plant mixed cold recycled mixture, the maximum dry density should be obtained by compaction test of the mixture before mixing with foamed asphalt to determine the optimal moisture content of the foamed asphalt plant mixed cold recycled mixture. According to the three gradations, the composite mixture with moisture content of 6.0, $6.5,7.0,7.5,8.0$ is used for compaction test to obtain the maximum dry density and the best moisture content of the aggregate. Taking $80 \%$ of the optimal water content of the aggregate to calculate the optimal mixing water consumption of the foamed asphalt cold recycled mixture, the test results are shown in Table 8.

Table 8. Determination of the optimal moisture content

\begin{tabular}{cccc}
\hline Design specifications & Gradation A & Gradation B & Gradation C \\
\hline Optimal water content $(\%)$ & 7.6 & 7.2 & 7.4 \\
Maximum dry density $\left(\mathrm{g} / \mathrm{cm}^{3}\right)$ & 2.073 & 2.042 & 2.059 \\
Optimal mixing water $(\%)$ & 6.1 & 5.8 & 5.9 \\
\hline
\end{tabular}

4.4 Determination of the best foaming conditions for asphalt

The determination of the optimal foaming conditions for asphalt is based on the expansion rate and halflife curves obtained by the foaming machine under different conditions of temperature and foaming water consumption, and the water consumption within the allowable range of expansion rate and halflife is determined to find the average value. That is, the optimal foaming water consumption, and then find the corresponding expansion rate and half-life in the expansion rate and half-life curve according to the optimal foaming water consumption, which is the optimal foaming condition of asphalt.

Select the temperature of $150^{\circ} \mathrm{C}, 160^{\circ} \mathrm{C}, 170^{\circ} \mathrm{Cand}$ the foaming water consumption of $1.5 \%, 2.0 \%$, $2.5 \%, 3.0 \%$ respectively to carry out the above test to determine the best foaming conditions of asphalt, its engineering design gradation and foaming The test results are shown in Table9 and Figures 4, 5 and 6.

Table 9. Engineering design gradation of recycled mixture

\begin{tabular}{cccccccccccccc}
\hline & \multicolumn{10}{c}{ Percentage (\%) } & passing the following sieve holes $(\mathbf{m m})$ \\
\hline Mineral material name & 31.5 & 26.5 & 19 & 16 & 13.2 & 9.5 & 4.75 & 2.36 & 1.18 & 0.6 & 0.3 & 0.15 & 0.075 \\
Gradation A & 100 & 97.3 & 90.4 & 81.2 & 70.6 & 60.3 & 49.7 & 41.3 & 32.8 & 23.6 & 21 & 12 & 5.3 \\
Gradation B & 100 & 96.1 & 85.5 & 75.4 & 64.8 & 56.6 & 44.6 & 37.2 & 29.2 & 19.9 & 15.3 & 9.3 & 4.8 \\
Gradation C & 100 & 91.3 & 81.2 & 69.4 & 61.2 & 53.4 & 42 & 33.6 & 25.7 & 17.1 & 12.9 & 7.8 & 4.1 \\
Specification limit & 100 & 78 & 70 & 65 & 60 & 50 & 40 & 30 & 20 & 15 & 10 & 6 & 3 \\
Lower specification limit & 100 & 100 & 95 & 90 & 85 & 75 & 60 & 50 & 40 & 32 & 25 & 20 & 15 \\
\hline
\end{tabular}




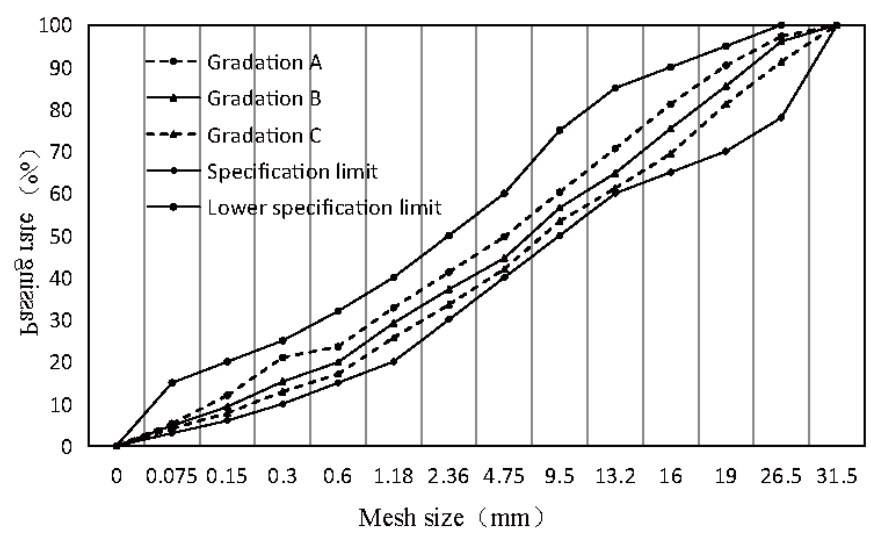

Figure 3. Test gradation curve of foamed asphalt mixture

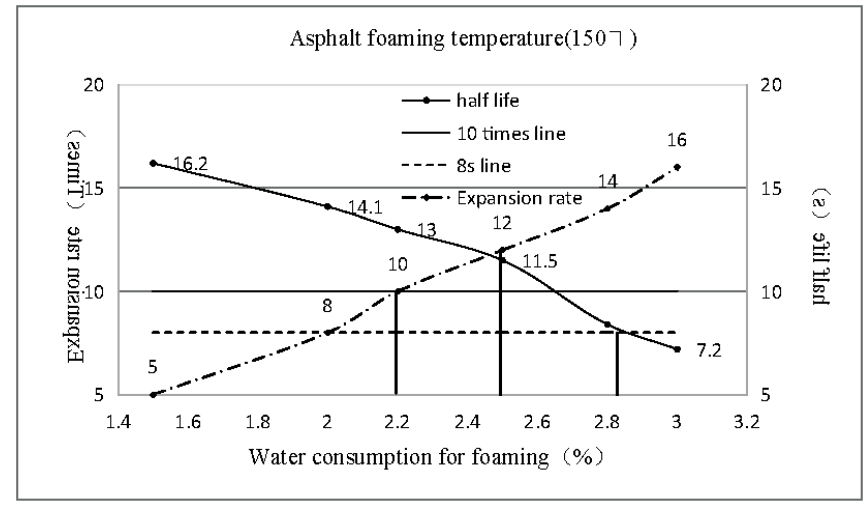

Figure 4. Foaming effect of foamed asphalt at $150^{\circ} \mathrm{C}$

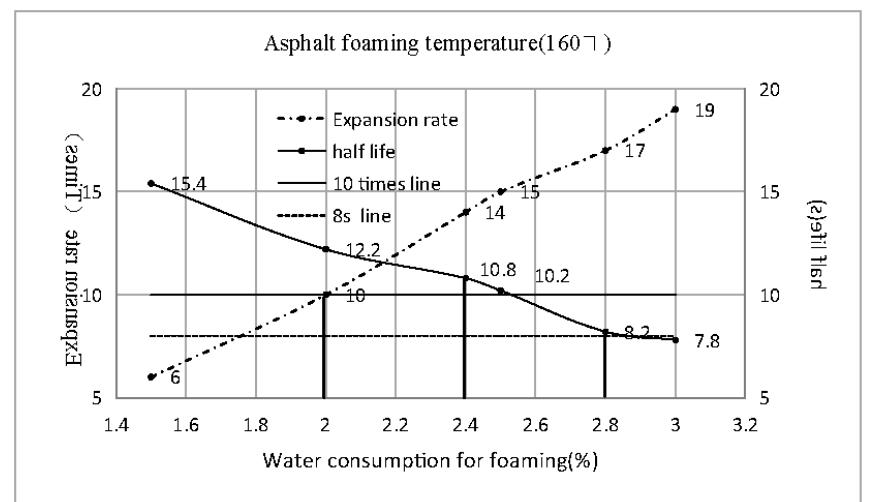

Figure 5. Foaming effect of foamed asphalt at $160^{\circ} \mathrm{C}$

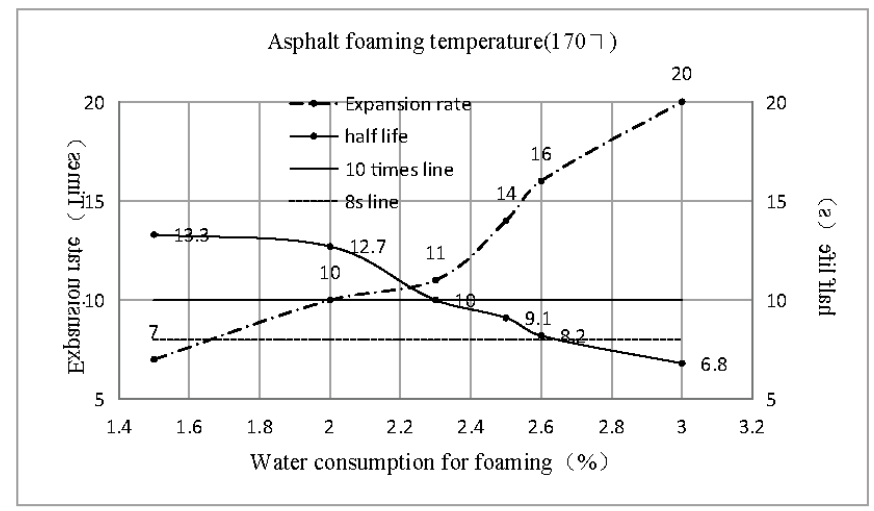

Figure 6. Foaming effect of foamed asphalt at $170^{\circ} \mathrm{C}$

From Figure 4 to Figure 6, it can be seen that the optimal foaming conditions at $150{ }^{\circ} \mathrm{C}, 160{ }^{\circ} \mathrm{C}$, and $170^{\circ} \mathrm{C}$ are shown in Table 10 .

Table 10. The best foaming conditions for asphalt

\begin{tabular}{cccc}
\hline Asphalt foaming temperature $\left({ }^{\circ} \mathbf{C}\right)$ & Water consumption for foaming (\%) & Expansion rate (Times) & half life (s) \\
\hline 150 & 2.5 & 12 & 11 \\
160 & 2.4 & 14 & 11 \\
170 & 2.3 & 11 & 10 \\
\hline
\end{tabular}

According to the principle of maximizing the sum of half-life and expansion rate, the optimal foaming temperature is determined to be $160^{\circ} \mathrm{C}$. After analysis, the half-life and expansion rate at $160^{\circ} \mathrm{C}$ meet the relevant requirements.

\section{Research on mechanical properties of foamed asphalt plant-mixed cold recycled mixture}

\subsection{Dry-wet splitting strength ratio}

Using the standard of $1.5 \%$ cement dosage and $0.3 \%$ increase or decrease of foamed asphalt dosage based on the theoretical dosage as the median value, the Marshall standard specimens of foamed asphalt plant mixed cold recycled mixture were made and dried and cured, and dry and wet splitting strength tests were carried out. The average value of the strength is used to calculate the dry-wet splitting strength ratio. The test results of the various allocation schemes are shown in Figure 7, Figure 8 and Figure 9.

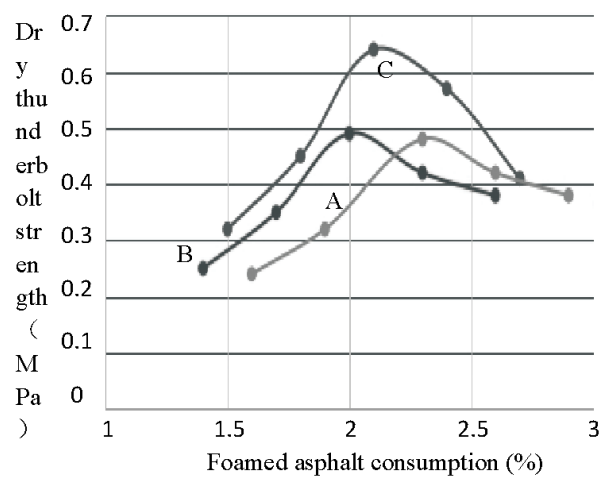

Figure 7. The relationship between the three-level distribution of dry thunderbolt and strong su and the change of foamed asphalt consumption 


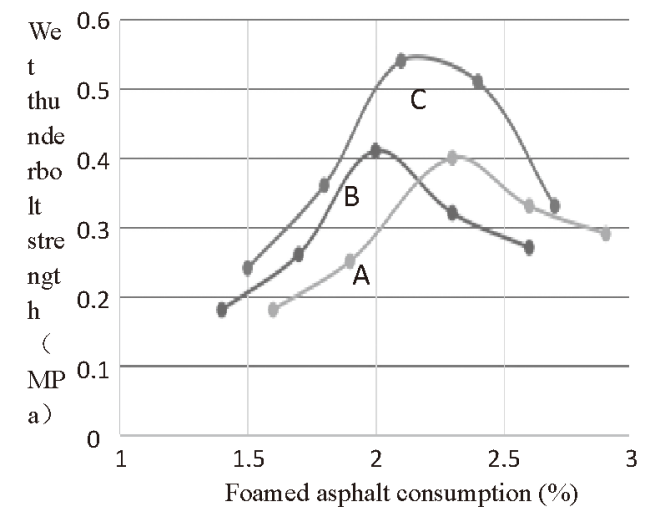

Figure 8. The relationship between the three-grade wet thunderbolt strength and the change of foamed asphalt consumption

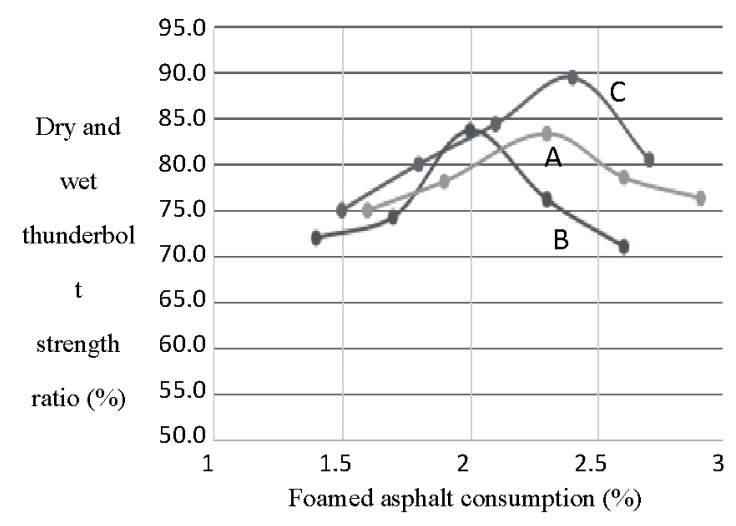

Figure 9. Three-level dry and wet thunderbolt strength ratio

It can be seen from the results of Figure 7-9 that the dry and wet thunderbolt strength and strength ratio of the gradation $\mathrm{C}$ foamed asphalt plant-mixed cold recycled mixture are better than the other two gradations of A and B under different asphalt content, so Grade $\mathrm{C}$ mixture is the best graded foamed asphalt plant-mixed cold recycled mixture. It can be seen from Figure 7 and Figure 8 that when the amount of foamed asphalt reaches $2.2 \%$, the dry splitting strength and wet splitting strength of gradation C are both at the maximum position; from Figure 9 it can be seen that when the amount of foamed asphalt reaches $2.2 \%$, the wet-dry splitting strength ratio is also within the specified range and meets the requirements, so $2.2 \%$ is selected as the design dosage of foamed asphalt.

\subsection{Unconfined compressive strength and dynamic stability}

The foamed asphalt cold recycled mixture was made with $2.2 \%$ foamed asphalt, and the unconfined compressive strength and dynamic stability were tested. After the test piece was molded and demolded and left for 24 hours at room temperature, it was dried for 48 hours and then placed in the air at a constant temperature of about $20^{\circ} \mathrm{C}$ for more than 6 hours to conduct an unconfined compressive strength test. The rutting specimens were molded and demolded and allowed to stand for 24 hours at room temperature, dried for 48 hours and then placed in the air at a constant temperature of $60^{\circ} \mathrm{C}$ for more than 24 hours. The rutting test was used to determine the dynamic stability test. The test results of unconfined compressive strength and dynamic stability are shown in Table 11.

Table 11. Unconfined compressive strength and dynamic stability test results

\begin{tabular}{ccccccc}
\hline $\begin{array}{c}\text { Asphalt } \\
\text { content } \mathbf{( \% )}\end{array}$ & $\begin{array}{c}\text { Marshall } \\
\text { Stability } \\
(\mathbf{k N})\end{array}$ & $\begin{array}{c}\text { Flow value } \\
\mathbf{( m m )}\end{array}$ & $\begin{array}{c}\text { Splitting } \\
\text { strength } \\
\mathbf{( 2 5} \mathbf{C}) \\
\mathbf{( M P a )}\end{array}$ & $\begin{array}{c}\text { Unconfined } \\
\text { compression } \\
\text { strength } \\
\mathbf{( M P a )}\end{array}$ & $\begin{array}{c}\text { Wet and dry } \\
\text { splitting } \\
\text { Intensity ratio } \\
(\mathbf{\%})\end{array}$ & $\begin{array}{c}\text { Dynamic } \\
\text { stability } \\
(\mathbf{T i m e s} / \mathbf{m m})\end{array}$ \\
\hline Detection value & 6.8 & 2.3 & 0.60 & 1.4 & 88.3 & 4472 \\
Skills requirement & $\geq 5.0$ & $1.5-4.5$ & $\geq 0.4$ & $\geq 1.2$ & $\geq 75$ & $\geq 4000$ \\
\hline
\end{tabular}

It can be seen from Table11 that the performance indicators of the foamed asphalt cold recycled mixture can meet the requirements.

\section{Conclusion}

Foamed asphalt plant mix cold recycling technology can reasonably and efficiently utilize the construction waste generated by milling, increase efficiency, energy conservation and environmental protection, save resources, and reduce construction costs; the foamed asphalt mixture has good gradation and good durability; foamed asphalt plant mix The cold recycling technology adds cement and other granular materials to effectively improve the shear strength of the foamed asphalt mixture and increase the fatigue resistance of the pavement structure.

Foamed asphalt plant mix cold recycling technology can make the construction waste generated during construction to be resourced and rationally used, reduce environmental pollution and engineering costs, and can be used in various road maintenance and reconstruction projects, and has 
certain practical value.

\section{References}

[1] "Design \& Construction Specification for Asphalt Pavement of Cold Recycling Layer with Foamed Bitumen" DB 33/T 7152008
[2] "Standard Test Methods of Bitumen and Bituminous Mixtures for Highway Engineering" JTG E20-2011

[3] "Test Methods of Aggregate for Highway Engineering" JTG E42-2005

[4] "Technical Specification for Highway Asphalt Pavement Recycling" JTG F41-2008 